\title{
UTCI field measurements in an urban park in Florence (Italy)
}

\begin{abstract}
The aim of this study is to evaluate human thermal comfort in different green area settings in the city of Florence by using the Universal Thermal Climate Index (UTCI). Field measurements of air temperature, solar radiation, relative humidity, wind speed and black globe thermometer were collected during hot summer days in various parts of Cascine Park, the biggest urban park in Florence (Italy). UTCI was evaluated over different surfaces (asphalt, gravel and grass) completely exposed to the sun or shaded by a large lime tree (Tilia $\times$ europaea). The results showed strong differences in UTCI values depending on the exposure to tree shade, while no significant difference was found among ground-cover materials when all surfaces were equally exposed to solar radiation. Future studies are needed to investigate the microclimatic effects of different tree species on UTCI.
\end{abstract}

Keywords

Thermal comfort $\bullet$ urban park $\cdot \mathrm{UTCl} \cdot$ biometeorology $\bullet$ tree shade

(๑) University of Warsaw - Faculty of Geography and Regional Studies

\author{
Martina Petralli $\mathbb{C}^{1,2}$, Luciano Massetti $\mathbb{C}^{3}$, \\ David Pearlmutter $\mathbb{C}^{3,4}$, Giada Brandani $\mathbb{C}^{2,5}$, \\ Alessandro Messeri $\mathbb{C}^{2}$, Simone Orlandini $\mathbb{C}^{2,5}$ \\ ${ }^{1}$ CIBIC-UNIFI - Center for Bioclimatology, University of \\ Florence, Florence, Italy \\ 2DAGRI-UNIFI - Department of Agriculture, Food, \\ Environment and Forestry, University of Florence, \\ Florence, Italy \\ ${ }^{3}$ BBE-CNR - Institute of Biometeorology, Italian National \\ Research Council, Florence, Italy \\ ${ }^{4}$ Ben-Gurion University of the Negev, Beersheba, Israel \\ ${ }^{5} \mathrm{FCS}$ - Foundation for Climate and Sustainability, \\ Florence, Italy \\ e-mails: martina.petralli@unifi.it; luciano.massetti@ibe.cnr.it; \\ davidp@bgu.ac.il; giada.brandani@unifi.it; alessandro.messer@@unifi.it; \\ simone.orlandini@unifi.it \\ Received: 19 December 2019 \\ Accepted: 20 April 2020
}

Introduction

The characteristics of both artificial and natural materials used within the urban environment have a decisive influence on the urban heat island and on human thermal comfort. Urban trees contribute to microscale cooling by evapotranspiration (Konarska et al. 2014; Oke 1989; Demuzere et al. 2014) and by intercepting solar radiation and reducing the heating of surfaces under their canopy (Holst et al. 2004; Lee et al. 2016; Zölch et al. 2016). Even though air temperature reductions in small green areas may be negligible, especially in conditions of high air turbulence, numerous studies confirm that tree shade can improve outdoor thermal comfort dramatically by reducing a pedestrian's exposure to both shortand long-wave radiation (Rahman \& Ennos 2016). Indeed, tree shade and ground-cover type (e.g. vegetation and paving) strongly affect surface temperature and can moderate air temperature, especially in the daytime (Brandani et al. 2016; Loveday et al. 2019). The characteristics of different tree species are also important; for example, the density of the canopy (as expressed by its leaf area index, or $\mathrm{LAI}$ ) and its seasonal variation affect the proportion of direct solar radiation that is absorbed or reflected by the tree (Shahidan et al. 2010; Napoli et al. 2016; Massetti et al. 2019).

Tree shade and surface type also affect the values of biometeorological indices that are used to evaluate human thermal comfort. These indices are typically calculated from meteorological variables, which may be quantified in different ways. For instance, a recent study comparing different ground surfaces and shading conditions (Pearlmutter et al. 2017) showed that the level of discomfort predicted for an area with highly reflective gravel was higher when using the Index of Thermal Stress (ITS) than it was when using the Universal Thermal Climate Index
(UTCI). The aim of this study is to evaluate the level of thermal stress that is generated on clear and sunny summer days for a series of different ground-cover surfaces and shade conditions, by using UTCI in particular.

\section{Materials and methods}

UTCl is an international standard (http://www.utci.org) defined by the European Cooperation in Science and Technology (COST) Action 730, based on recent research in human responserelated thermo-physiological modelling (Gosling et al. 2014; Coccolo et al. 2016). It is expressed as the equivalent air temperature $\left({ }^{\circ} \mathrm{C}\right)$ of a reference environment that would produce the same human physiological response as the actual environment. In this case, the human physiological response to meteorological input is based on Fiala's (Fiala et al. 2001) multi-node model of human thermoregulation (Jendritzky et al. 2012; Blazejczyk el al. 2012). The UTCI categories of heat stress are defined as follows: above +46 - extreme heat stress; +38 to +46 - very strong heat stress; +32 to +38 - strong heat stress; +26 to $+32-$ moderate heat stress; +9 to +26 - no thermal stress (Bröde et al. 2012).

The study was conducted in an area of Cascine Park adjacent to the School of Agronomy (Fig. 1). The effect of tree shading and ground material properties on thermal comfort were investigated by assessing the Universal Thermal Climate Index (UTCI) over exposed gravel (Exp Gravel), asphalt (Exp Asphalt) and grass (Exp Grass) as well as tree-shaded asphalt (S Asphalt). The albedo of the monitored surfaces was measured and the results showed 0.18 for asphalt, 0.36 for gravel and 0.25 for grass. In the summer of 2014 , measurements of air temperature (Ta), relative 

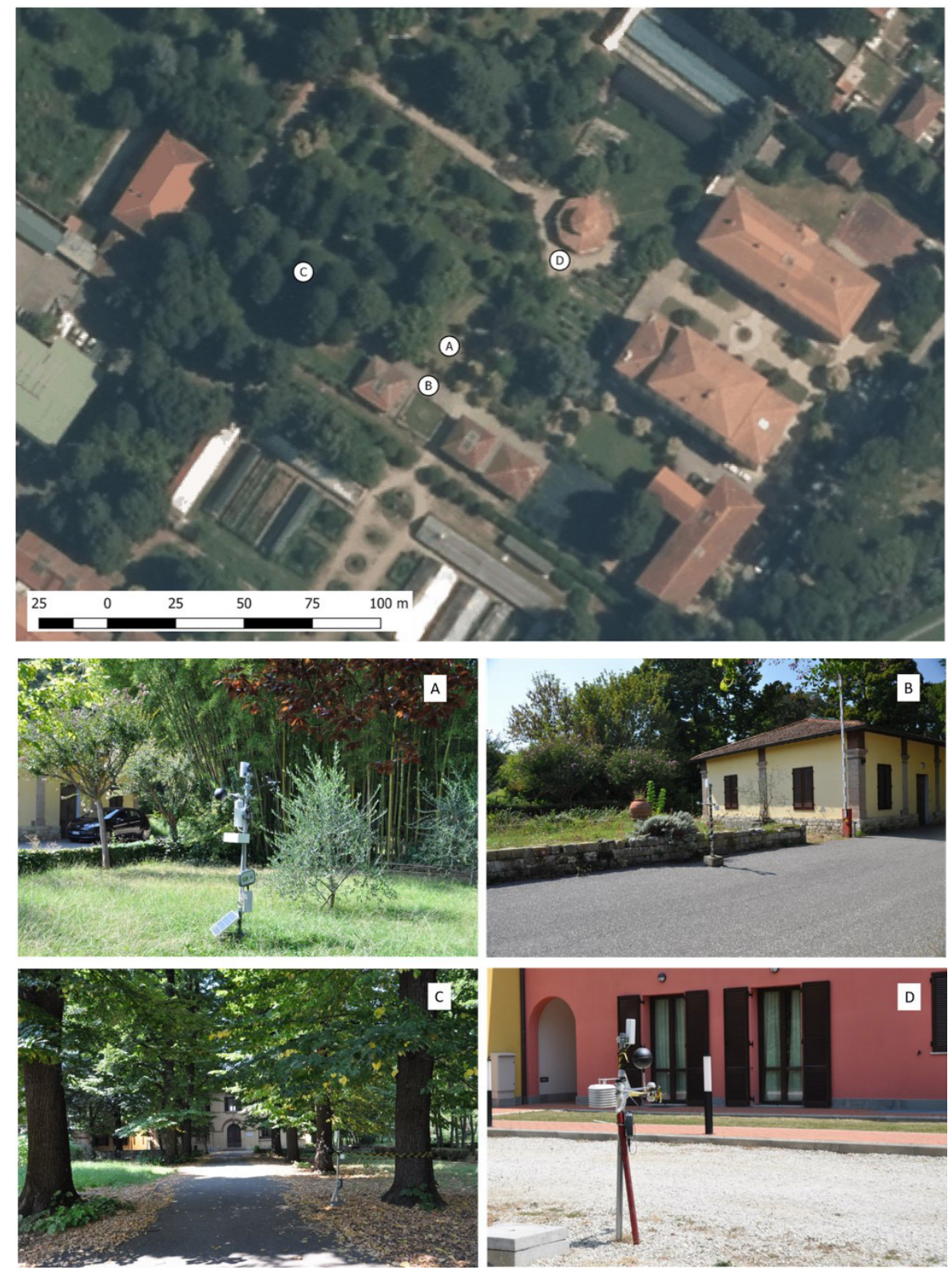

Figure 1. Study area and location of the micrometeorological stations: $A$ ) sun-exposed grass (Exp Grass); B) exposed asphalt (Exp Asphalt); C) shaded asphalt (S Asphalt); and D) exposed gravel (Exp Gravel). Source: figures A-B-C-D - own study; map own study created by using OpenStreetMap®, Geoscopio WMS and QGIS 3.2.3, http://qgis.osgeo.org.

humidity $(\mathrm{RH})$, wind speed and globe temperature $(\mathrm{Tg})$ were taken during calm and clear days using four micrometeorological stations located at 1.7 metres above the respective surfaces (Figure 1). All of the micrometeorological stations were located within a radius of less than 100 metres. Each micrometeorological station was equipped with sensors for measuring air temperature (Ta) $\left({ }^{\circ} \mathrm{C}\right)$, relative humidity (Thermo-hygrometer PS-0062$\mathrm{AD}$, Netsens) (\%), solar radiation $\left(\mathrm{MJ} \mathrm{m}^{-2}\right.$ ) (Global radiation sensor, Netsens), wind speed $\left(\mathrm{ms}^{-1}\right)$ (Anemometer 6410, Davis Instruments Corp.) and globe temperature (Pt100 sensor, globe $\varnothing 150 \mathrm{~mm}$, Delta OHM). Mean radiant temperature (MRT, based on $\mathrm{Tg}$ ) and the above-mentioned meteorological parameters were used to calculate UTCl. Data were collected every 15 minutes, and hourly averages were calculated for data analysis.
Results

Measurements were taken during typically calm and sunny summer days in Florence. During the summer of 2014, a total of 7 days (2-4 July and 15-18 July), in clear sky conditions and without wind, were monitored by a weather station located near the study area. Maximum daily air temperature during the study period was $32.5 \pm 1.7^{\circ} \mathrm{C}$, daily mean relative humidity was $61 \%$, mean wind speed was $0.3 \mathrm{~ms}^{-1}$ and maximum solar radiation was $844 \pm 83 \mathrm{~W} / \mathrm{m}^{2}$.

A comparison of Ta, MRT and UTCl over the four surfaces shows that daily mean and maximum values over S Asphalt were lower than those over the other surfaces in all cases (Table 1). The average daily temperature over the 'dry' surfaces (asphalt and gravel), when exposed to the sun, was nearly $1.5^{\circ} \mathrm{C}$ higher 
Table 1. Daily mean, maximum and minimum values of air temperature $\left(\mathrm{Ta},{ }^{\circ} \mathrm{C}\right)$ collected at the reference weather station located near the study area (Ref), over sun-exposed grass (Exp Grass), asphalt (Exp Asphalt) and gravel (Exp Gravel), and over tree-shaded asphalt (S Asphalt), together with calculated mean values of mean radiant temperature $\left(M R T,{ }^{\circ} \mathrm{C}\right)$ and Universal Thermal Climate Index $\left(\mathrm{UTCl},{ }^{\circ} \mathrm{C}\right)$ over the same four surfaces

\begin{tabular}{|c|c|c|c|c|c|c|}
\hline & & Ref & Exp Grass & Exp Asphalt & S Asphalt & Exp Gravel \\
\hline \multirow{3}{*}{$\mathrm{Ta}$} & mean & 26.1 & 26.3 & 27.4 & 25.9 & 27.5 \\
\hline & $\max$ & 32.5 & 32.9 & 35.0 & 31.0 & 35.1 \\
\hline & $\min$ & 18.3 & 18.5 & 19.4 & 19.6 & 18.9 \\
\hline \multirow{3}{*}{ MRT } & mean & & 36.9 & 39.5 & 26.0 & 40.0 \\
\hline & $\max$ & & 66.1 & 67.2 & 38.8 & 63.8 \\
\hline & $\min$ & & 17.4 & 18.4 & 19.4 & 17.7 \\
\hline \multirow{3}{*}{ UTCI } & mean & & 27.8 & 29.5 & 25.4 & 29.7 \\
\hline & $\max$ & & 41.7 & 44.6 & 32.6 & 44.1 \\
\hline & $\min$ & & 17.4 & 18.4 & 18.8 & 18.0 \\
\hline
\end{tabular}

Source: own study

than that recorded at the weather station, while differences of only $+/-0.2{ }^{\circ} \mathrm{C}$ relative to the reference station were observed over Exp Grass and S Asphalt. In terms of mean radiant temperature (MRT), the most striking differences were seen between the shaded and exposed asphalt surfaces - with the latter having a higher daily mean (by nearly $14{ }^{\circ} \mathrm{C}$ ) and a much higher peak value (by over $28^{\circ} \mathrm{C}$ ). Calculating UTCI over the four surfaces, the mean value over S Asphalt was 25.4 - corresponding to 'no thermal stress' - while the mean UTCl reached values corresponding to 'moderate thermal stress' over all the other surfaces (Table 1).

When comparing the hourly values of Ta, Tg, MRT and UTCI, the differences between shaded and exposed surfaces were even more evident (Table 2). During the daytime, air temperature values over Exp Asphalt and Exp Gravel were on average $2{ }^{\circ} \mathrm{C}$ higher than Exp Grass, and $4{ }^{\circ} \mathrm{C}$ higher than S Asphalt. Maximum air temperatures were recorded over all surfaces and exposures at $1 \mathrm{p} . \mathrm{m}$. The differences in minimum daily temperatures were reversed, with $18.5^{\circ} \mathrm{C}$ recorded over Exp Grass and $19.6^{\circ} \mathrm{C}$ over $\mathrm{S}$ Asphalt. The minimum values of $\mathrm{Tg}$ and MRT were collected one or two hours later than the minimum Ta over all the surfaces observed: over Exp Grass at 5 a.m. and the other surfaces at 6 a.m., with a difference between surfaces of almost $2{ }^{\circ} \mathrm{C}$. Maximum values of $\mathrm{Tg}$ and MRT were recorded between 1 p.m. and 2 p.m. for all exposed surfaces, whereas $S$ Asphalt reached maximum Tg and MRT at 5 p.m.

During the night-time and the early morning - until sunrise - the surface with the lowest Ta value was Exp Grass, followed by Exp Gravel.

During the early morning, minimum Ta over $\mathrm{S}$ Asphalt was almost $1^{\circ} \mathrm{C}$ higher than over Exp Grass - and only $0.5^{\circ} \mathrm{C}$ higher than Exp Gravel and $0.2^{\circ} \mathrm{C}$ higher than Exp Asphalt (Table 2).

The results show that the most dramatic reduction in thermal stress, as expressed by UTCI, occurred over surfaces shaded by trees: in these areas a pedestrian would be exposed to conditions defined as 'moderate heat stress' for nearly all the hours of a typical summer day (Figure 2).

Over the irrigated grass lawn, which had a low surface temperature and albedo, hot conditions were maintained for only a brief time in the afternoon.
According to UTCI, both Exp Gravel and Exp Asphalt produced very strong heat stress during daytime hours. The very small distinction between these two surfaces is likely due to the lack of sensitivity of the black globe thermometer to the effects of reflected solar radiation from gravel, which was interspersed with other materials, on the body. A pedestrian in the unshaded gravel and asphalt area would experience a degree of heat stress for the full daytime period: from one hour after sunrise (7 a.m.) to sunset (8 p.m.), the UTCl values exceeded $26{ }^{\circ} \mathrm{C}$ for a total of 13 hours during the daytime under heat stress conditions. The same pedestrian, if standing on grass exposed to sunlight, would experience a total amount of 12 hours of heat stress; while standing under tree shade they would experience a total amount of 10 hours of heat stress.

Whether standing exposed to sunlight or under tree shade also changes the degree of heat stress experienced by people. Over Exp Gravel and Asphalt, during typical sunny and calm days, a pedestrian would experience 2 hours of moderate heat stress (from 7 to 8 a.m. and from 7 to 8 p.m.), 3 hours of strong heat stress (from 8 to 10 a.m. and from 6 to 7 p.m.) and 8 hours of very strong heat stress (from 10 a.m. to 6 p.m.). When standing on grass exposed to sunlight, they would experience 3 hours of moderate heat stress (from 8 to 9 a.m. and from 6 to 8 p.m.), 4 hours of strong heat stress (from 9 to 12 a.m. and from 5 to 6 p.m.) and 5 hours of very strong heat stress, from 12 a.m. to 5 p.m.). Finally, a person standing in tree shade would experience 8 hours of moderate heat stress (from 10 a.m. to 3 p.m. and from 5 p.m. to 8 p.m.) and 2 hours of strong heat stress (from 3 to 5 p.m.). The two hours of severe heat stress observed during the study period for people standing in tree shade were characterized by values very close to the lower threshold of the thermal stress category (Figure 2).

Finally, air temperature and UTCI trends were observed over exposed and shaded asphalt (Figure 3). UTCI values, both in sun-exposed and shaded conditions, maintain similar values to air temperature during the night (between 7 p.m and 5 a.m.). The air temperature differences between exposed and tree-shaded asphalt were of almost $3-4{ }^{\circ} \mathrm{C}$. Maximum differences of almost $10-15^{\circ} \mathrm{C}$ were observed during the daytime between UTCI over exposed asphalt and tree-shaded asphalt. Over tree-shaded 
MISCELLANEA GEOGRAPHICA - REGIONAL STUDIES ON DEVELOPMENT

Vol. $24 \cdot$ No. $3 \cdot 2020 \cdot$ pp. 111-117 • ISSN: 2084-6118 • DOI: 10.2478/mgrsd-2020-0017

Table 2. Hourly mean values (expressed as mean \pm standard deviation) of air temperature $\left(\mathrm{Ta}\right.$, $\left.{ }^{\circ} \mathrm{C}\right)$, black globe temperature $\left(\mathrm{Tg},{ }^{\circ} \mathrm{C}\right)$, and mean radiant temperature $\left(\mathrm{MRT},{ }^{\circ} \mathrm{C}\right)$ collected at 1.7 metres over sun-exposed grass (Exp Grass), asphalt (Exp Asphalt) and gravel (S Gravel) and over tree-shaded asphalt (S Asphalt)

\begin{tabular}{|c|c|c|c|c|c|c|c|c|c|c|c|c|}
\hline & \multicolumn{4}{|c|}{$\mathrm{Ta}$} & \multicolumn{4}{|c|}{$\mathrm{Tg}$} & \multicolumn{4}{|c|}{ MRT } \\
\hline $\mathbf{H}$ & $\begin{array}{l}\text { Exp } \\
\text { Grass }\end{array}$ & $\begin{array}{c}\text { Exp } \\
\text { Asphalt }\end{array}$ & $\begin{array}{c}\text { S } \\
\text { Asphalt }\end{array}$ & $\begin{array}{l}\text { Exp } \\
\text { Gravel }\end{array}$ & $\begin{array}{l}\text { Exp } \\
\text { Grass }\end{array}$ & $\begin{array}{c}\text { Exp } \\
\text { Asphalt }\end{array}$ & $\begin{array}{c}\text { S } \\
\text { Asphalt }\end{array}$ & $\begin{array}{l}\text { Exp } \\
\text { Gravel }\end{array}$ & $\begin{array}{l}\text { Exp } \\
\text { Grass }\end{array}$ & $\begin{array}{c}\text { Exp } \\
\text { Asphalt }\end{array}$ & $\begin{array}{c}\text { S } \\
\text { Asphalt }\end{array}$ & $\begin{array}{c}\text { Exp } \\
\text { Gravel }\end{array}$ \\
\hline 0 & $21.1 \pm 1.9$ & $21.1 \pm 1.4$ & $21.9 \pm 1.7$ & $20.6 \pm 1.3$ & $21.7 \pm 1.2$ & $21.6 \pm 1.4$ & $23.0 \pm 1.6$ & $20.5 \pm 1.1$ & $20.9 \pm 0.1$ & $21.6 \pm 1.4$ & $23.1 \pm 1.8$ & $20.5 \pm 1.1$ \\
\hline 1 & $20.5 \pm 2.1$ & $20.4 \pm 1.4$ & $21.1 \pm 1.6$ & $20.0 \pm 1.3$ & $21.3 \pm 2.8$ & $20.8 \pm 1.3$ & $22.2 \pm 1.5$ & $19.9 \pm 1.2$ & $20.8 \pm 2.1$ & $20.8 \pm 1.3$ & $22.5 \pm 2.0$ & $19.9 \pm 1.2$ \\
\hline 2 & $19.8 \pm 1.5$ & $19.9 \pm 1.5$ & $20.4 \pm 1.2$ & $19.5 \pm 1.5$ & $20.4 \pm 2.9$ & $20.3 \pm 1.4$ & $21.7 \pm 1.6$ & $19.4 \pm 1.2$ & $20.4 \pm 2.9$ & $20.3 \pm 1.4$ & $21.7 \pm 1.6$ & $19.4 \pm 1.2$ \\
\hline 3 & $19.0 \pm 1.2$ & $19.5 \pm 1.3$ & $19.8 \pm 1.2$ & $18.9 \pm 1.4$ & $19.1 \pm 1.4$ & $19.9 \pm 1.5$ & $20.9 \pm 1.1$ & $19.3 \pm 1.2$ & $19.1 \pm 1.4$ & $19.9 \pm 1.5$ & $20.9 \pm 1.1$ & $19.3 \pm 1.2$ \\
\hline 4 & $18.5 \pm 1.1$ & $19.4 \pm 1.1$ & $19.6 \pm 1.0$ & $19.1 \pm 0.9$ & $18.2 \pm 1.3$ & $19.4 \pm 1.6$ & $20.3 \pm 1.1$ & $18.6 \pm 1.7$ & $18.2 \pm 1.3$ & $19.4 \pm 1.6$ & $20.3 \pm 1.1$ & $18.6 \pm 1.7$ \\
\hline 5 & $18.8 \pm 1.7$ & $21.2 \pm 1.2$ & $20.5 \pm 1.3$ & $22.5 \pm 0.6$ & $17.5 \pm 0.9$ & $18.8 \pm 1.4$ & $19.7 \pm 1.0$ & $18.0 \pm 1.5$ & $17.4 \pm 0.9$ & $18.8 \pm 1.4$ & $19.7 \pm 1.0$ & $18.0 \pm 1.5$ \\
\hline 6 & $20.4 \pm 2.0$ & $24.8 \pm 1.2$ & $22.2 \pm 1.4$ & $25.3 \pm 0.6$ & $18.0 \pm 1.6$ & $18.4 \pm 1.3$ & $19.4 \pm 1.2$ & $17.7 \pm 1.1$ & $18.0 \pm 1.6$ & $18.4 \pm 1.3$ & $19.4 \pm 1.2$ & $17.7 \pm 1.1$ \\
\hline 7 & $22.9 \pm 2.7$ & $27.9 \pm 0.6$ & $24.0 \pm 1.4$ & $27.4 \pm 0.5$ & $21.9 \pm 2.0$ & $20.7 \pm 0.9$ & $20.6 \pm 1.1$ & $20.5 \pm 1.0$ & $22.2 \pm 2.1$ & $19.1 \pm 2.9$ & $19.4 \pm 1.4$ & $18.9 \pm 3.0$ \\
\hline 8 & $26.1 \pm 3.0$ & $30.3 \pm 0.8$ & $26.1 \pm 1.8$ & $30.3 \pm 0.8$ & $25.1 \pm 1.6$ & $25.8 \pm 0.2$ & $22.6 \pm 1.1$ & $36.0 \pm 1.1$ & $26.8 \pm 1.2$ & $23.1 \pm 0.7$ & $20.2 \pm 1.7$ & $38.9 \pm 2.1$ \\
\hline 9 & $28.9 \pm 2.8$ & $31.9 \pm 0.7$ & $27.9 \pm 2.0$ & $32.2 \pm 1.0$ & $37.7 \pm 1.1$ & $40.7 \pm 1.4$ & $24.7 \pm 1.0$ & $41.0 \pm 1.5$ & $47.7 \pm 2.1$ & $45.9 \pm 3.3$ & $22.3 \pm 1.6$ & $46.2 \pm 3.2$ \\
\hline 10 & $30.6 \pm 2.5$ & $33.2 \pm 0.9$ & $29.2 \pm 1.6$ & $33.3 \pm 0.9$ & $41.5 \pm 4.3$ & $43.8 \pm 1.3$ & $26.6 \pm 1.1$ & $43.8 \pm 0.8$ & $55.8 \pm 6.7$ & $55.5 \pm 4.0$ & $23.0 \pm 3.2$ & $55.5 \pm 3.8$ \\
\hline 11 & $31.5 \pm 2.3$ & $33.3 \pm 2.3$ & $29.8 \pm 1.6$ & $33.5 \pm 2.3$ & $41.4 \pm 3.7$ & $44.6 \pm 2.6$ & $28.1 \pm 1.3$ & $45.1 \pm 2.9$ & $58.4 \pm 7.0$ & $60.4 \pm 3.4$ & $25.1 \pm 1.4$ & $61.5 \pm 6.6$ \\
\hline 12 & $32.4 \pm 2.2$ & $34.1 \pm 2.2$ & $30.5 \pm 1.6$ & $34.2 \pm 1.9$ & $44.0 \pm 2.3$ & $47.1 \pm 3.8$ & $29.6 \pm 1.2$ & $45.6 \pm 2.9$ & $60.5 \pm 5.9$ & $64.0 \pm 2.0$ & $28.3 \pm 1.1$ & $61.0 \pm 1.6$ \\
\hline 13 & $32.9 \pm 2.0$ & $35.0 \pm 1.5$ & $31.0 \pm 1.3$ & $35.1 \pm 1.0$ & $44.0 \pm 2.3$ & $48.3 \pm 3.6$ & $30.0 \pm 0.9$ & $46.6 \pm 2.6$ & $60.5 \pm 5.9$ & $64.6 \pm 2.0$ & $28.5 \pm 1.0$ & $61.3 \pm 1.8$ \\
\hline 14 & $32.4 \pm 1.4$ & $33.8 \pm 2.2$ & $30.4 \pm 2.0$ & $34.0 \pm 2.2$ & $47.8 \pm 1.7$ & $47.6 \pm 1.7$ & $30.4 \pm 1.7$ & $46.0 \pm 2.4$ & $66.1 \pm 1.6$ & $67.2 \pm 1.6$ & $30.3 \pm 1.5$ & $63.8 \pm 4.7$ \\
\hline 15 & $32.3 \pm 1.9$ & $33.4 \pm 1.8$ & $30.3 \pm 1.3$ & $33.3 \pm 1.8$ & $41.8 \pm 6.2$ & $44.2 \pm 2.3$ & $30.7 \pm 1.9$ & $42.1 \pm 2.3$ & $54.1 \pm 1.5$ & $60.7 \pm 2.1$ & $31.5 \pm 2.9$ & $55.8 \pm 1.6$ \\
\hline 16 & $31.7 \pm 1.5$ & $31.1 \pm 1.4$ & $29.7 \pm 1.1$ & $32.7 \pm 2.1$ & $44.9 \pm 0.1$ & $38.6 \pm 1.3$ & $31.6 \pm 0.8$ & $40.3 \pm 3.3$ & $58.5 \pm 0.9$ & $50.5 \pm 5.5$ & $34.6 \pm 1.0$ & $52.4 \pm 1.7$ \\
\hline 17 & $30.0 \pm 1.1$ & $29.6 \pm 1.2$ & $29.1 \pm 1.0$ & $30.6 \pm 1.3$ & $31.6 \pm 0.4$ & $43.9 \pm 1.6$ & $33.1 \pm 1.9$ & $45.0 \pm 3.4$ & $33.4 \pm 0.5$ & $62.1 \pm 2.6$ & $38.8 \pm 3.9$ & $63.1 \pm 5.2$ \\
\hline 18 & $28.8 \pm 1.1$ & $27.9 \pm 1.2$ & $28.0 \pm 1.1$ & $28.0 \pm 1.3$ & $30.1 \pm 0.9$ & $37.6 \pm 5.1$ & $29.7 \pm 1.3$ & $37.4 \pm 4.7$ & $31.5 \pm 0.5$ & $50.5 \pm 13.9$ & $31.8 \pm 2.1$ & $49.8 \pm 13$ \\
\hline 19 & $27.3 \pm 1.4$ & $26.4 \pm 0.9$ & $26.7 \pm 1.2$ & $26.3 \pm 1.2$ & $28.7 \pm 0.3$ & $30.5 \pm 1.5$ & $29.1 \pm 1.2$ & $39.2 \pm 0.9$ & $29.3 \pm 1.0$ & $34.7 \pm 1.5$ & $31.4 \pm 1.7$ & $51.2 \pm 3.6$ \\
\hline 20 & $25.8 \pm 1.5$ & $24.7 \pm 0.4$ & $25.2 \pm 1.3$ & $24.4 \pm 0.5$ & $26.3 \pm 1.9$ & $28.2 \pm 1.2$ & $27.9 \pm 1.1$ & $27.9 \pm 1.3$ & $26.0 \pm 1.7$ & $30.6 \pm 3.7$ & $30.0 \pm 2.6$ & $30.2 \pm 3.6$ \\
\hline 21 & $24.2 \pm 1.5$ & $23.1 \pm 1.0$ & $23.9 \pm 1.5$ & $22.6 \pm 0.8$ & $24.3 \pm 2.6$ & $25.9 \pm 0.9$ & $26.4 \pm 1.2$ & $25.5 \pm 0.9$ & $23.6 \pm 2.5$ & $27.3 \pm 1.7$ & $27.8 \pm 2.0$ & $26.9 \pm 1.7$ \\
\hline 22 & $22.7 \pm 1.7$ & $22.2 \pm 1.3$ & $23.3 \pm 1.7$ & $21.6 \pm 1.1$ & $23.5 \pm 1.6$ & $24.3 \pm 0.7$ & $25.1 \pm 1.2$ & $23.5 \pm 0.8$ & $22.7 \pm 1.9$ & $24.3 \pm 0.7$ & $25.3 \pm 1.0$ & $23.5 \pm 0.8$ \\
\hline 23 & $22.0 \pm 2.0$ & $21.4 \pm 1.4$ & $22.3 \pm 1.7$ & $20.9 \pm 1.4$ & $23.4 \pm 1.7$ & $22.7 \pm 0.7$ & $23.8 \pm 1.2$ & $21.8 \pm 0.9$ & $23.0 \pm 1.2$ & $22.7 \pm 0.7$ & $24.1 \pm 1.5$ & $21.8 \pm 0.9$ \\
\hline
\end{tabular}

Source: own study

asphalt, UTCI showed values similar to the air temperature (both exposed and tree-shaded) during the daytime.

\section{Discussion}

The results of this study show the effect of tree shade on human thermal comfort: the air temperature during hot sunny days over sun-exposed asphalt is almost $3^{\circ} \mathrm{C}$ higher than over tree-shaded asphalt, while the UTCI can be higher by $15^{\circ} \mathrm{C}$, passing from strong to moderate heat stress. Urban trees can have a pronounced effect on the microclimatic conditions of their immediate vicinity, and they can relieve the burden of thermal stress experienced by pedestrians. As tree canopies shade not only the person's body but also the surrounding ground or built surfaces, lower radiant temperatures are maintained, which causes these surfaces to emit less intense long-wave radiation and, at the same time, to reflect less short-wave radiation onto the person's body (Pearlmutter et al. 2017). The influence of vegetation and trees on thermal comfort is well documented: in Florence, it was found that a $10 \%$ increase in the percentage of greenery surrounding a micrometeorological station could prevent 30 hours of summer discomfort (Petralli et al. 2015).

In recent years, research has increasingly focused on the shading effect of different tree species (Armson et al. 2012; Napoli et al. 2016; Shahidan et al. 2010): Napoli and collaborators collected data on 10 different tree species in order to estimate surface temperatures under different shade conditions. In Munich, 


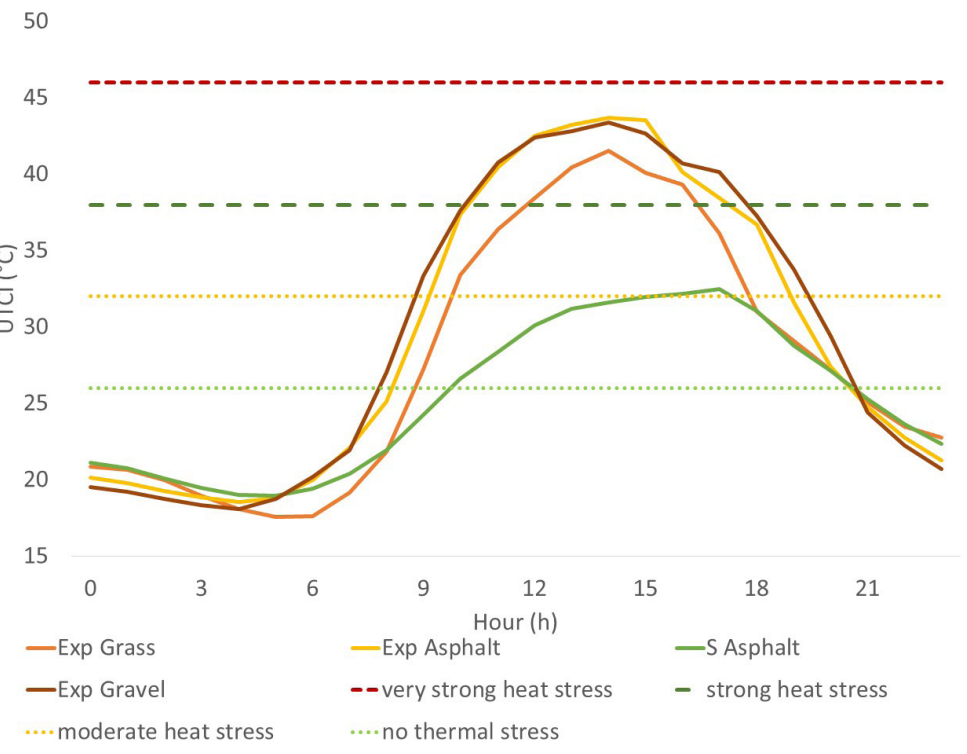

Figure 2. Hourly values of the Universal Thermal Climate Index (UTCI, $\left.{ }^{\circ} \mathrm{C}\right)$ observed during sunny, hot and calm summer days in Cascine Park in Florence and corresponding to levels of thermal sensation for pedestrians over sun-exposed grass (Exp Grass), asphalt (Exp Asphalt), gravel (Exp Gravel) and tree-shaded asphalt (S Asphalt), and corresponding categories of UTCI thermal stress. Source: own study

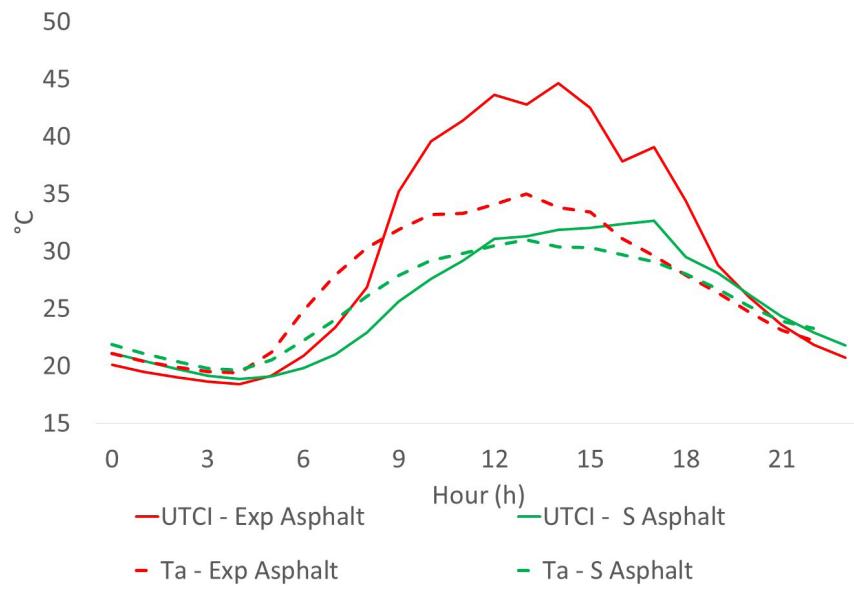

Figure 3. Hourly values of the air temperature $\left(\mathrm{Ta},{ }^{\circ} \mathrm{C}\right)$ and Universal Thermal Climate Index $\left(\mathrm{UTCl},{ }^{\circ} \mathrm{C}\right)$ observed during sunny, hot and calm summer days in Cascine Park in Florence over sun-exposed asphalt (Ta Exp Asphalt, red dashed line, and UTCI Exp Asphalt, red line, respectively) and over tree-shaded asphalt (Ta S Asphalt, green dashed line, and UTCI S Asphalt, green line, respectively). Source: own study

Robinia pseudoacacia L. and Tilia cordata Mill. were compared in terms of surface cooling potential and significant differences were observed (Rahman et al. 2019). All these results suggest that thermal comfort can be influenced by the characteristics of tree canopies, and this influence is especially apparent when thermal comfort is evaluated using biometeorological indices that includes radiation or variables linked to radiation (such as soil temperature or globe temperature).

During the daytime, the maximum air temperature was recorded over all surfaces and exposures at 1 p.m. Maximum values of $\mathrm{Tg}$ and MRT were recorded between 1 p.m. and
2 p.m. for all exposed surfaces, while tree-shaded asphalt reached maximum $\mathrm{Tg}$ and MRT at 5 p.m.; this time lag reflects the fact that solar input peaks around noon but environmental temperatures peak later in the afternoon. This is expected, as tree crowns reduce the penetration of short-wave solar radiation and lower the temperature of surfaces in their shade (Roy et al. 2012). Furthermore, as tree canopies are not homogeneous, solar radiation passes through them with different intensity during the day according to solar angles, canopy branching and leaf percentages (Kotzen, 2003). 
This study shows that during the night-time and the early morning the surface with the lowest Ta value is exposed grass, followed by exposed gravel (Table 2). This result confirms previous studies that assessed the cooling effect of permeable surfaces, especially during the night (Wang \& Banzhaf 2018; Shashua-Bar et al. 2009). In a previous study performed in Florence (Petralli et al. 2014), the minimum daily temperature at a given location was affected by the degree of urbanization surrounding it (an increase of $10 \%$ in the proportion of grassland in a buffer area of 500 metres around a location could cause a $0.6{ }^{\circ} \mathrm{C}$ reduction in minimum temperature). With regard to the early morning, the results of this study show that the presence of a tree canopy reduces the heat loss for radiative processes during the night and this can reduce air and surface temperature cooling (Armson et al. 2012).

The use of vegetation provides clear benefits compared to dry asphalt and gravel, though irrigated grass that is fully exposed to the sun has an especially low 'cooling efficiency' due to its high water consumption. Both Exp Gravel and Exp Asphalt produced very strong heat stress during daytime hours. The very small distinction between these two surfaces is likely due to the increased sensitivity of the black globe thermometer to direct solar radiation, especially in the middle of the day (Khrit et al. 2017), and this could account for the low effect due to reflected solar radiation by different surfaces. A pedestrian in the unshaded gravel and asphalt area would experience a degree of heat stress for the full daytime period. Whether standing exposed to sunlight or under tree shade also changes the degree of heat stress experienced by people.

For thermal stress evaluated with UTCI, our results suggest that the most effective treatment for reducing thermal stress under hot and clear conditions is to ensure that direct radiation does not reach a pedestrian's body or the surrounding ground surfaces, regardless of their albedo. Some authors found that an increase of ground albedo or the albedo of walls would lead to an increase in the UTCI linked to an increase in mean radiant temperatures (Schrijvers et al. 2016). However, other studies found that albedo plays a significant role in mean radiant temperature values during winter, but not during summer (Huang et al. 2019). These different findings can also be linked to the method of measuring or estimating mean radiant temperature in outdoor environments (Thorsson et al. 2007; Krüger et al. 2014).

\section{Conclusion}

The present study confirms the role of trees and tree shade in cooling the surrounding air and improving outdoor thermal comfort dramatically by reducing the exposure of a pedestrian to both short- and long-wave radiation (Pearlmutter et al. 2014; ShashuaBar et al. 2011).

The main results of this study on UTCl are summarized as follows:

- During typical clear and sunny days, a person standing on unshaded surfaces can be exposed to severe heat stress conditions for a long period during the day.

- Over gravel surfaces, which have a higher albedo than asphalt, the UTCI heat stress is the same as over asphalt: this is likely due to the lack of sensitivity of the globe thermometer to the effects of reflected solar radiation on the human body.

- A dramatic reduction in UTCI was observed for the treeshaded asphalt - with heat stress in this case limited to 'moderate' throughout the daytime hours.

- When sunlight reaches the micrometeorological station by passing through the tree canopy, Tg and UTCl suddenly increase; this underlines the importance the density of the tree canopy has on thermal comfort.

Future studies:

- place micrometeorological stations at different heights above the ground;

- evaluate the radiative effect of surfaces on $\mathrm{Tg}$ at lower heights above the ground;

- place micrometeorological stations under different tree species and canopy management methods, in order to evaluate thermal comfort and microclimatic conditions according to these variables.

\section{ORCID}

Martina Petralli (D) https://orcid.org/0000-0003-0221-0776

Luciano Massetti (D) https://orcid.org/0000-0002-0941-5347

David Pearlmutter (1D https://orcid.org/0000-0002-0775-6770

Giada Brandani (D) https://orcid.org/0000-0002-3182-1464

Alessandro Messeri (i) https://orcid.org/0000-0001-8220-811X

Simone Orlandini (1D https://orcid.org/0000-0001-6290-9752

\section{References}

Armson, D, Stringer, P \& Ennos, AR 2012, 'The effect of tree shade and grass on surface and globe temperatures in an urban area', Urban Forestry \& Urban Greening, vol. 11, pp. 245- 255.

Blazejczyk, K, Epstein, Y, Jendritzky, G, Staiger, H \& Tinz, B 2012, 'Comparison of UTCI to selected thermal indices', International Journal of Biometeorology, vol. 56, pp. 515535.

Brandani, G, Napoli, M, Massetti, L, Petralli, M \& Orlandini, S 2016, 'Urban soil: Assessing ground cover impact on surface temperature and thermal comfort', Journal of Environmental Quality, vol. 45, no. 1, pp. 90-97.

Bröde, P, Fiala, D, Błażejczyk, K, Holmér, I, Jendritzky, G, Kampmann, B, Tinz, B \& Havenith, G 2012, 'Deriving the operational procedure for the Universal Thermal Climate Index (UTCI)', International Journal of Biometeorology, vol. 56, no. 3, pp. 481-494

Coccolo, S, Kämpf, J, Scartezzini, JL \& Pearlmutter, D 2016, 'Outdoor human comfort and thermal stress: A comprehensive review on models and standards', Urban Climate vol. 18, pp. 33-57.
Demuzere, M, Orru, K, Heidrich, O, Olazabal, E, Geneletti, D, Orru, H, Bhave, AG, Mittal, N, Feliu, E \& Faehnle, M 2014 'Mitigating and adapting to climate change: multi-functional and multi-scale Assessment of green urban infrastructure', Journal of Environmental Management, vol. 146, pp. 107115.

Fiala, D, Lomas, KJ \& Stohrer, M 2001, 'Computer prediction of human thermoregulatory and temperature responses to a wide range of environmental conditions', International Journal of Biometeorology, vol. 45, pp. 143-159.

Gosling, SN, Bryce, EK, Dixon, PG, Gabriel, KMA, Gosling, EY, Hanes, JM, Hondula, DM, Liang, L, Bustos Mac Lean, PA, Muthers, S, Nascimento, ST, Petralli, M, Vanos, JK \& Wanka, ER 2014, 'A glossary for biometeorology', International journal of biometeorology, vol. 58, no. 2, pp. 277-308.

Huang, Z, Gou, Z \& Cheng, B 2020, 'An investigation of outdoor thermal environments with different ground surfaces in the hot summer-cold winter climate region', Journal of Building Engineering, vol. 27, no.100994.

Holst, TH, Hauser, S, Kirchgäßner, A, Matzarakis, A, Mayer, H \& Schindler, D 2004, 'Measuring and modelling plant 
area index in beech stands'. International Journal of Biometeorology, vol. 48, no 4, pp. 192-201.

Jendritzky, G, De Dear, R \& Havenith, G 2012, 'UTCI - why another thermal index?', International Journal of Biometeorology, vol. 56, no. 2, pp. 421-428.

Khrit, NG, Alghoul, MA, Sopian, K, Lahimer, AA \& Elayeb, OK 2017, 'Assessing the accuracy of globe thermometer method in predicting outdoor mean radiant temperature under malaysia tropical microclimate', E3S Web of Conferences, 23: 01006.

Kotzen, B 2003, 'An investigation of shade under six different tree species of the Negev desert towards their potential use for enhancing micro-climatic conditions in landscape architectural development', Journal of Arid Environments, vol. 55, pp. 231-274.

Konarska, J, Lindberg, F, Larsson, A, Thorsson, S \& Holmer, B 2014, 'Transmissivity of solar radiation through crowns of single urban trees-application for outdoor thermal comfort modelling', Theoretical and Applied Climatology, vol. 117, pp. 363-376.

Krüger, EL, Minella, FO \& Matzarakis, A 2014, 'Comparison of different methods of estimating the mean radiant temperature in outdoor thermal comfort studies', International Journal Biometeorology, vol. 58, pp. 1727-1737.

Lee, H, Mayer, H \& Chen, L 2016, 'Contribution of trees and grasslands to the mitigation of human heat stress in a residential district of Freiburg, Southwest Germany'. Landscape and Urban Planning, vol. 148, pp. 37-50.

Loveday, J, Loveday, G, Byrne, JJ, Ong, BL \& Morrison, GM 2019, 'Seasonal and diurnal surface temperatures of urban landscape elements', Sustainability, vol. 11, no. 19, pp. 1-27.

Massetti, L, Petralli, M, Napoli, M, Brandani, G, Orlandini, S \& Pearlmutter, D 2019, 'Effects of deciduous shade trees on surface temperature and pedestrian thermal stress during summer and autumn', International Journal of Biometeorology, vol. 63, no. 4, pp. 467-479.

Napoli, M, Massetti, L, Brandani, G, Petralli, M \& Orlandini, S 2016, 'Modeling tree Shade effect on urban ground surface temperature', Journal of Environmental Quality, vol. 45, no. 1, pp. $146-156$.

Oke, TR 1989, 'The micrometeorology of the urban forest', Philosophical Transactions of the Royal Society B, vol. 324, pp. 335-349.

Pearlmutter, D, Jiao, D \& Garb, Y 2014, 'The relationship between bioclimatic thermal stress and subjective thermal sensation in pedestrian spaces', International. Journal of Biometeorology, vol. 58, no. 10, pp. 2111-2127.

Pearlmutter. D, Petralli, M, Massetti, L, Napoli, M, Brandani, G \& Orlandini, S 2017, 'Park design and pedestrian thermal stress: evaluating the effect of shade and ground surface materials', PLEA proceedings Design to Thrive, vol. 2, pp. 1837-1840.

Petralli, M, Massetti, L, Brandani, G \& Orlandini, S 2014, 'Urban planning indicators: useful tools to measure the effect of urbanization and vegetation on summer air temperatures' International Journal of Climatology, vol. 34, no. 4, pp. 1236-1244.

Petralli, M, Brandani, G, Napoli, M, Messeri, A \& Massetti, L 2015, 'Thermal comfort and green areas in Florence', Italian Journal of Agrometeorology, vol. 2, pp. 39-48.

Rahman, MA \& Ennos, AR 2016, What we know and don't know about the cooling benefits of urban trees, Technical Report, Trees \& Design Action Group. Available from: < https://www. researchgate.net/publication/303868184_What_we_know_ and_don't_know_about_the_cooling_benefits_of_urban_ trees>. [12 January 2020].
Rahman, MA, Moser, A, Rötzer, T \& Pauleit, S 2019, 'Comparing the transpirational and shading effects of two contrasting urban tree species', Urban Ecosystems, vol. 22, no. 4, pp. 683-697.

Roy, S, Byrne, J \& Pickering, C 2012, 'A systematic quantitative review of urban tree benefits, costs, and assessment methods across cities in different climatic zones', Urban Forestry \& Urban Greening, vol. 11, no. 4, pp. 351- 363.

Schrijvers, PJC, Jonker, HJJ, de Roode, SR \& Kenjeres, S 2016, 'The effect of using a high-albedo material on the Universal Temperature Climate Index within a street canyon', Urban Climate, vol. 7, pp. 284- 303.

Shahidan, MF, Shariff, MKM, Jones, P, Salleh, E \& Abdullah, A M 2010, 'A comparison of Mesua ferrea L. And Hura crepitans L. for shade creation and radiation modification in improving thermal comfort', Landscape and Urban Planning, vol. 97, pp. $168-181$.

Shashua-Bar, L, Pearlmutter, D \& Errel, E 2009, 'The cooling efficiency of urban landscape strategies in a hot dry climate', Landscape and Urban Planning, vol. 92, no. 3-4, pp. 179186.

Shashua-Bar, L, Pearlmutter, D \& Erell E 2011, 'The influence of trees and grass on outdoor thermal comfort in a hot-arid environment', International Journal of Climatology, vol. 31, no. 10, pp. 1498-1506.

Thorsson, S, Lindberg, F, Eliasson, I \& Holmer, B 2007, 'Different methods for estimating the mean radiant temperature in an outdoor urban setting', International Journal of Climatology, vol. 27, 1893-1983.

Wang, J \& Banzhaf, E 2018, 'Towards a better understanding of green infrastructure: a critical review', Ecological Indicators, vol. 85, pp. 758-772.

Zölch, T, Maderspacher, J, Wamsler, C \& Pauleit, S 2016, 'Using green infrastructure for urban climate-proofing: An evaluation of heat mitigation measures at the micro-scale', Urban Forestry \& Urban Greening, vol. 20, pp. 305-316. 